\title{
EJERCICIO DE LA ACCIÓN PENAL POR PARTICULAR: ¿DERECHO PROCESAL PENAL SIMBÓLICO?
}

\section{PRIVATE PROSECUTION: SYMBOLIC CRIMINAL PROCEDURAL LAW?}

\section{Resumen}

$\mathrm{E}$ n el presente artículo se analiza desde una postura crítica la eficacia del acceso a la justicia en la Ciudad México. Se toman en consideración posturas académicas, Derecho comparado, legislación, antecedentes jurídicos y estadísticos, todo desde un punto de vista sintético para llegar a aproximaciones específicas en relación al ejercicio de la acción penal por particular. El acceso a la justicia es un derecho humano que faculta a los particulares para ejercer acción penal, institución que forma parte de la expansión del derecho procesal penal, que a su vez, atendiendo a los requisitos someros de ley, la abrumadora incidencia delictiva, la exigüidad de participación de las víctimas y la obnubilación del Estado, hacen de esta un claro ícono de un Derecho Procesal Penal Simbólico. Cabe destacar que en atención a la escasa información pública, es complejo dimensionar el impacto jurídico-social, por lo cual es importante señalar que uno de los principales beneficios en el ejercicio de la acción penal por particular es la certeza jurídica a la que la víctima se vería sujeta en caso de proceder la controversia llevada a escrutinio judicial, ello en atención a la pericia de los operadores del sistema procesal penal acusatorio.

Palabras clave: Ejercicio de la Acción Penal por Particular; Sistema Penal Acusatorio; Acceso a la Justicia; Víctima; Derecho Procesal Penal Simbólico.

\begin{abstract}
I $n$ the present article it will be analyzed from critical posture the effectiveness of access to justice in Mexico City. Considering analyzing the academics stands, comparative law, legal and statistics antecedents, from the synthetic point of view until get particular approach related to private prosecution which is a human right that empowers the particular's, giving them the faculties to practice private prosecution, this institution takes part of the growth of criminal procedural law at the same time heeding superficially to the law requirements, the overwhelming crime incidence rate, dismissive victim's participation, state decreased consciousness, makes from this institution a clear icon of a Symbolic Criminal Procedural Law. It
\end{abstract}

1 Licenciado en Derecho por el Instituto Universitario Puebla IUP-CDMX; abogado postulante y estudiante en la Especialidad “Amparo Penal” (2019-2020) y la Maestría “Juicio Oral y Proceso Penal Acusatorio" (2018-2020) ambas del Instituto Nacional de Ciencias Penales (INACIPE); Ciudad de México; victorantonioderpenal@gmail.com 
is worth stressing that attending to the lack of public information it is extremely complex to value the socio-legal scope that impact at the society, it is need to emphasize that one of the principal benefits of private practice is the victim legal certainty in case to proceed the judge study of private prosecution, heeding to private procedure operator's expertise.

Key words: Private Prosecution; System of Criminal Justice; Access to Justice; Victim; Symbolic Criminal Procedural Law.

\section{Introducción}

El Ejercicio de la Acción Penal por Particular (EAPP) tiene su origen teórico en el abolicionismo penal (alternativa democrática a la justicia penal), mismo que surge del interaccionismo simbólico (modelo teórico de reacción) que "[...] reconoce solo la necesidad de encontrar algún mecanismo de resolución pacífica de los conflictos”, ${ }^{2}$ por su parte, Zamora Grant, dice:

\section{[...] los abolicionistas demostraron que existen alterna- tivas al sistema penal, que esas alternativas compensan más a la víctima que al sistema penal y que en tanto se pueden minimizar los daños que provoca el sistema penal. Aun cuando nunca pretendieron explotarlo a todo el mundo, es evidente que sus preocupaciones e incluso sus propuestas se han ido reflejando paulatina- mente en las tendencias legislativas de muchas partes del mundo, y México no es la excepción. ${ }^{3}$}

Por su parte Nils Christie advierte que la palabra "privado" proviene de "raíces latinas. Privere, privar, el concepto romano para el destino de ser amputado, separado

2 Zamora Grant, José. Derecho victimal: la víctima en el nuevo sistema penal mexicano. INACIPE. Ciudad de México, 2018, p. 53.

3 Ibídem, p. 70. 
de la vida social, arrancado de todo lo importante, apartado" (sic).4

En este tenor, las víctimas son separadas y tomadas en cuenta en asuntos de interés mediático, mismas que se encuentran urgidas de mecanismos eficaces de acceso a la justicia; es así que, el EAPP es una figura jurídico-procesal novedosa en la praxis mexicana y una alternativa -probablemente- eficaz para que el particular, es decir, la víctima directa o indirecta del delito tenga acceso a la justicia, cabe mencionar que el acceso a la justicia en nuestro país es sumamente precario, luego entonces, el EAPP representa una alternativa para reclamar justicia y que la víctima se vea reparada. Lo anterior en función de los objetivos del origen abolicionista del EAPP que se propone en el presente trabajo.

A partir de la reforma constitucional de junio de 2008 se implementa el actual Sistema de Justicia Penal Acusatorio en México, entrando en vigor el 18 de junio de 2016 en su totalidad; la Constitución Federal y el Código Nacional de Procedimientos Penales (CNPP) contemplan el EAPP como un derecho humano para que las víctimas directas o indirectas del delito (particulares) ejerzan la acción procedimental antes referida de algún hecho que la ley señale como delito.

Dicho lo anterior, hasta hace unos años la idea de que el Agente del Ministerio Pú-

4 Christie, Nils. Una sensata cantidad de delito. Editores del Puerto. Buenos Aires, 2004, p. 47. blico (AMP) contaba con el monopolio de la acción penal, parecía incontrovertible, sin embargo, con la referida reforma constitucional ello cambió y el EAPP podría resultar eficaz tanto para la autoridad (liberando cargas de trabajo), como para la sociedad, para poder tener acceso a la justicia de forma expedita; es entonces que el presente proyecto surge de la necesidad de investigar el parámetro de eficacia de dicha acción para conocer su alcance, beneficios e infortunios; luego, el EAPP podría ser un medio que permita a las víctimas del delito, poner a consideración el escrutinio en torno a la victimización a que fueron sometidas a fin de que un Juez de Control resuelva de forma jurídico-institucional, administrando en realidad no otra cosa que la violencia pese a esta nueva posibilidad, que en la actualidad no ha permeado lo suficiente, resultando un procedimiento especial (EAPP) desaprovechado por los particulares como una posible estrategia de litigio, teniendo en cuenta lo establecido en la norma penal vigente que resulta -en mi opinión- ser insuficiente, en virtud de que son muy pocos los tipos penales procedentes para su ejercicio. Por otro lado, las personas perciben al procedimiento especial, como un proyecto cuyo éxito sería utópico en razón que no tienen información al respecto y los que cuentan con la información son en su mayoría profesionales en el ámbito jurídico que tampoco han potencializado el uso de la institución. 
Por su parte, la doctrina ha planteado manuales forenses del ejercicio de la acción y diversas hipótesis en relación al acceso a la justicia, advirtiendo que dicha facultad "se muestra como la de mayor fuerza en la participación de la víctima en el proceso penal, al tener en sus manos no solo la incoación, sino la tramitación del procedimiento penal; sin embargo, esta fortaleza puede ser engañosa”, 5 además de existir pronunciamientos de tesis aisladas respecto de la improcedencia del amparo en la vía directa y las hipótesis de procedencia del EAPP.

Asimismo con la finalidad de inducir al lector a la presente investigación se contextualiza partiendo del siguiente objetivo: analizar la eficacia y acceso a la justicia conforme al EAPP, planteando el siguiente problema: ¿Cuáles son los efectos jurídicos de la reforma constitucional de 2008 que otorga la facultad potestativa a los particulares para ejercer la acción penal? Actualmente diversos juristas en el ámbito académico se han pronunciado respecto del EAPP, relacionando al procedimiento especial con la materia civil, advirtiendo el alto nivel técnico que deben tener los operadores del sistema, la analogía equívoca respecto de la privatización del Derecho Penal o señalando que el EAPP es una institución procesal penal en desuso; cabe destacar que tanto en el ámbito interna-

5 Zamora Grant, José. La víctima en el proceso penal acusatorio. UNAM. México, 2014, p. 107. cional como en el nacional, después de una exhaustiva investigación, se advierte que no se encontraron informes públicos que nos permitan medir los infortunios o éxitos del EAPP, salvo en la Ciudad de México; en este orden de ideas, el presente trabajo de investigación es un análisis crítico del EAPP para develarlo como lo que es: una institución jurídico procesal penal simbólica cuyos fines distan mucho del fortalecimiento de los derechos de las víctimas.

\section{Metodología}

El perfil de la presente investigación es teórica, ya que tiene como principal objetivo la obtención de conocimientos prescindiendo de la aplicabilidad de las conclusiones, haciendo énfasis en la interpretación de términos técnico-jurídicos.

Por otro lado, se utilizará el método deductivo, en razón que la información obtenida se analizará desde una generalidad hacia una particularidad, también el método cualitativo procesando la información para poder conocer el comportamiento de las diversas variables frente al problema, y cuantitativo, analizando los datos a través de la medición.

\section{Acceso a la justicia}

El artículo 17 párrafo $2 .^{\circ}$ constitucional establece que: "Toda persona tiene derecho a que se le administre justicia por tribunales que estarán expeditos para impartirla 
en los plazos y términos que fijen las leyes, emitiendo sus resoluciones de manera pronta, completa e imparcial. Su servicio será gratuito, quedando en consecuencia, prohibidas las costas judiciales”. Luego, las víctimas en su carácter de persona (física o jurídica) tienen derecho a solicitar acceder a la justicia mediante un tribunal que de forma independiente y bajo el principio de división de poderes, resuelva jurídico-institucionalmente, ello con respeto a la dignidad humana, reconociendo todos los derechos humanos que le asisten sin distinción, siendo un derecho absoluto que no debe restringirse, entonces, "la justicia será pronta y expedita siempre y cuando se respeten con exactitud los plazos dados por la ley misma”, ${ }^{6}$ considerando que la prontitud disminuirá la revictimización a la que están comúnmente expuestas las personas, y en su caso será completa cuando se tengan "los medios necesarios para el ejercicio de todos los derechos que la propia ley les otorga". 7 Lo anterior, en relación con el artículo $10^{\circ} \mathrm{y}$ 20, apartado C de la Constitución Federal y como ideal, la Declaración sobre los Principios Fundamentales de Justicia para las Víctimas de Delitos y del Abuso de Poder: “5. Se establecerá y reforzarán, cuando sea necesario, mecanismos judiciales y administrativos que permitan a las víctimas obtener reparación mediante proce-

6 Zamora Grant, José. Derecho victimal: la víctima en el nuevo sistema penal mexicano, op. cit, p. 155.

7 Ibid, p. 156. dimientos oficiales $u$ oficiosos que sean expeditos, justos, poco costosos y accesibles. Se informará a las víctimas de sus derechos para obtener reparación mediante esos mecanismos". Normatividad de observancia para el Estado mexicano para la creación de mecanismo eficaces y tan necesarios para que las víctimas puedan acceder a una reparación del daño; además, dicho estándar internacional maximiza el espectro de regulación jurídica al respecto del tema que nos ocupa, teniendo en consecuencia un derecho humano de doble fuente frente a un parámetro de regularidad constitucional. Sin omitirlo, el mismo artículo 17 constitucional prohíbe la venganza de mano propia, es así que en un contexto histórico la figura que nos ocupa tiene su origen en la venganza privada, periodo violento y lleno de impunidad; seguida de una época talonaria, en donde se buscaba que el daño producido en consecuencia fuera el mismo que se provocaba en nombre de la víctima (ojo por ojo), que desemboca en una venganza pública ahora denominada justicia, facultando al Estado quien con su imperium, ejerce el monopolio legítimo de la violencia mediante su poder punitivo. En este tenor, no se puede hablar de justicia si no se conoce el término "venganza", mismo que logró desde nuestros orígenes el desbordamiento de sangre inocente que incluso puso en peligro la humanidad por medio de la violencia, y por supuesto, siguiendo 
a Fernando Tenorio, el término "jus", ${ }^{8}$ no como tradicionalmente lo conocemos en el sentido de "derecho" sino como "fuerza”, que justamente legitima al Estado en la administración de la venganza y la violencia; pues como afirma René Girard, "El sistema judicial aleja la amenaza de la venganza. No la suprime: la limita efectivamente a una represalia única".?

Por su parte, Chul Han dice que "la justicia genera un movimiento que es opuesto a la estructura de congregación de poder". ${ }^{10}$ Es así que "poder significa imponerse a sí mismo a otro; en cierto sentido, crecer por encima del otro, predominar sobre el otro, es decir, continuarse a sí mismo en el otro o tender una continuidad, una continuación de sí mismo a lo largo del otro". ${ }^{11}$ Luego entonces, la acción procesal que nos ocupa puede resultar ser generadora de movimiento en oposición al AMP, de ello dependerá su debida substanciación; es decir, mientras el particular solicita acceder a la justicia, obteniendo una solución al conflicto mediante una forma alterna al proceso o inclusive una sentencia condenatoria que como resultado podría obtener una reparación del daño, y el imputado en consecuencia tendría la sanción

$8 \quad$ Cfr. Tenorio Tagle, Fernando. El delito y el control del delito en la modernidad avanzada. Publicia. Alemania, 2014.

9 Girard, René. La violencia y lo sagrado. Anagrama. Barcelona, 1983, p. 23.

10 Chul Han, Byung. Sobre el poder. Herder. España, 2016, p. 169.

11 Ibídem, p. 165. correspondiente. Por otro lado, en aras de conseguir generar dicho movimiento, el particular que por necesidad de requerir diligencias que impliquen un acto de molestia, este deberá solicitarlo a un Juez de Control, mismo que le dará intervención al AMP -a la estructura de poder que en primera instancia no se acudió-. En este tenor, de ser procedente, el particular podrá tener certeza jurídica de su asunto de forma expedita, pero no así la certeza de acceder a la justicia ante un sistema procesal penal, en virtud que el particular deberá tener los medios necesarios para dar en todo momento continuidad a su asunto, resultando en primera instancia aislado de la posibilidad de seguir con la dirección de la investigación, por lo que en consecuencia, se desprende que si el titular del EAPP solicita un acto de molestia que no constituya control judicial, recurre al AMP y si lo es, comparece ante el Juez de Control, pero en ambos supuestos pierde la titularidad de la acción. Así las cosas, en términos de Chul Han, el titular del EAPP es un sujeto de rendimiento que, al requerir de mayor facultades, este fracasa, dando paso al infierno de lo igual (acción pública) en un sistema procesal penal cansado que requiere de la necesaria continuidad de la estructura de poder facultada para ejercer acción penal (AMP). 
"El sujeto de rendimiento se explota a sí mismo, hasta que se derrumba", ${ }^{12}$ por su parte una sociedad del rendimiento es aquella "que nos aísla", ${ }^{13}$ luego entonces, la víctima en el proceso penal es un ser aislado por el propio sistema, particular que al procurar ejercer acción penal culmina por explotarse a sí mismo, siendo la gestión en general y/o los recursos que implica dicho ejercicio un mayor desgaste, que el delito mismo por el que persigue tener acceso a la justicia, por lo que el particular, por virtud del supuesto poder punitivo que le ha sido conferido pero que también es susceptible de perder, se traduce en la pérdida de la dirección de la investigación, aunque si logra cumplir con los requisitos, el particular habrá alcanzado la finalidad del ejercicio de la acción penal que es llevar el escrutinio de una controversia ante un Juzgador, perdiendo la titularidad el Estado, lo cual dado el entramado jurídico, se vislumbra complicado.

\section{Procedencia}

Siguiendo la base constitucional del artículo 21 párrafo 2. : " "El ejercicio de la acción penal ante los tribunales corresponde al Ministerio Público. La ley determinará los casos en que los particulares podrán ejercer la acción penal ante la autoridad judicial”. El artículo 428 del CNPP establece

12 Chul Han, Byung. En el enjambre. Herder. Barcelona, 2019, p. 76.

13 Ídem. que: "La víctima u ofendido podrá ejercer la acción penal únicamente en los delitos perseguibles por querella, cuya penalidad sea alternativa, distinta a la privativa de la libertad o cuya punibilidad máxima no exceda de tres años de prisión”. Es decir, se actualizan dos hipótesis de procedencia del EAPP, en los delitos que se persiguen por querella, en aquellos: a) cuya penalidad sea alternativa, distinta a la privativa de libertad o b) cuya punibilidad máxima no exceda de tres años de prisión; ${ }^{14}$ en este orden, la normatividad refiere que el requisito de procedibilidad sine qua non es la querella, ello, por virtud de la gama de delitos que son susceptibles para el EAPP respecto de la penalidad alternativa distinta a la privativa de la libertad o la punibilidad máxima que no exceda de tres años de prisión, confusión que podría desembocar en un infortunio de litigio procesal. De acuerdo con lo anterior, en la Ciudad de México se actualiza su procedencia para los siguientes tipos penales:

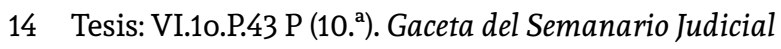
de la Federación. 10. época. Libro 53. Abril de 2018. Tomo III, p. 1889. 
Tabla 1. Tipos penales

\section{Código Penal para el Distrito Federal (ahora CDMX)}

\begin{tabular}{|c|c|c|c|c|}
\hline Núm. & $\begin{array}{l}\text { Artículo, fracción } \\
\text { y/o párrofo }\end{array}$ & Delitos & Supuesto de procedencia & Observación \\
\hline 1 & Art. 130 F. II & Lesiones & $\begin{array}{l}\text { Perseguibles por querella, } \\
\text { punibilidad máxima no excede } \\
\text { de tres años de prisión. }\end{array}$ & \\
\hline 2 & $\begin{array}{l}\text { Art. } 130 \text { F. III, } \\
\text { IV, V, VI, VII }\end{array}$ & Lesiones & $\begin{array}{c}\text { Perseguibles por querella } \\
\text { y punibilidad máxima no excede } \\
\text { de tres años de prisión. }\end{array}$ & $\begin{array}{c}\text { Artículos aplicables: } \\
76 \text { (naturaleza culposa), y } 135 \\
\text { (en caso de lesiones por conductor } \\
\text { en acción libre en su causa } \\
\text { provocada por si, o abandono } \\
\text { de víctima, no procederá como } \\
\text { delito culposo). }\end{array}$ \\
\hline 3 & Art. 159 & Peligro de contagio & $\begin{array}{c}\text { Perseguibles por querella, } \\
\text { punibilidad máxima no excede } \\
\text { de tres años de prisión } \\
\text { y de cincuenta a trescientos } \\
\text { días multa. }\end{array}$ & $\begin{array}{l}\text { No procederá en caso que } \\
\text { la enfermedad padecida fuera } \\
\text { incurable. }\end{array}$ \\
\hline 4 & Art. 179 & Acoso sexual & $\begin{array}{c}\text { Perseguibles por querella } \\
\text { y punibilidad máxima no excede } \\
\text { de tres años de prisión. }\end{array}$ & \\
\hline 5 & Art. 206 & Discriminación & $\begin{array}{l}\text { Perseguibles por querella, } \\
\text { punibilidad máxima no excede } \\
\text { de tres años de prisión o de } \\
\text { veinticinco a cien días de trabajo } \\
\text { en favor de la comunidad y multa } \\
\text { de cincuenta a doscientos días. }\end{array}$ & \\
\hline 6 & Art. 209 & Amenazas & $\begin{array}{l}\text { Perseguibles por querella } \\
\text { y punibilidad máxima no } \\
\text { excede de tres años de prisión } \\
\text { o de noventa a trescientos } \\
\text { sesenta días multa. }\end{array}$ & \\
\hline 7 & Art. 209 BIS & $\begin{array}{c}\text { Delito de cobranza } \\
\text { ilegítima }\end{array}$ & $\begin{array}{l}\text { Perseguibles por querella, } \\
\text { punibilidad máxima no excede de } \\
\text { tres años de prisión y una multa } \\
\text { de ciento cincuenta a trescientos } \\
\text { días de salario mínimo. }\end{array}$ & \\
\hline 8 & Art. 210 & $\begin{array}{l}\text { Allanamiento } \\
\text { de morada, } \\
\text { despacho, oficina } \\
\text { o establecimiento } \\
\text { mercantil }\end{array}$ & $\begin{array}{l}\text { Perseguibles por querella, } \\
\text { punibilidad máxima no excede } \\
\text { de tres años de prisión o de } \\
\text { cincuenta a cien días multa. }\end{array}$ & \\
\hline
\end{tabular}




\begin{tabular}{|c|c|c|c|c|}
\hline 9 & Art. 211 Quáter & $\begin{array}{l}\text { Uso indebido } \\
\text { de los servicios } \\
\text { de llamadas de } \\
\text { emergencia }\end{array}$ & $\begin{array}{l}\text { Perseguibles por querella, } \\
\text { punibilidad máxima no excede } \\
\text { de tres años de prisión y multa } \\
\text { de diez a cien unidades cuantifica- } \\
\text { bles de medida y actualización. }\end{array}$ & \\
\hline 10 & Art. 220 F. II & Robo & $\begin{array}{l}\text { Perseguibles por querella, } \\
\text { punibilidad máxima no excede } \\
\text { de tres años de prisión y sesenta } \\
\text { a ciento cincuenta días multa. }\end{array}$ & \\
\hline 11 & $\begin{array}{c}\text { Art. } 221 \mathrm{~F} \text {. II } \\
\text { (hipótesis en poder } \\
\text { de otra persona) }\end{array}$ & Robo & $\begin{array}{l}\text { Perseguibles por querella, } \\
\text { punibilidad máxima no excede } \\
\text { de tres años de prisión y sesenta } \\
\text { a ciento cincuenta días multa. }\end{array}$ & $\begin{array}{l}\text { Siempre y cuando el valor de lo } \\
\text { robado actualice las hipótesis } \\
\text { de procedencia del artículo } 220 \\
\text { fracción II. }\end{array}$ \\
\hline 12 & $\begin{array}{l}\text { Art. } 222 \\
\text { (hipótesis sin con- } \\
\text { sentimiento) }\end{array}$ & Robo & $\begin{array}{l}\text { Perseguibles por querella, } \\
\text { punibilidad máxima no excede } \\
\text { de tres años de prisión o de } \\
\text { treinta a noventa días multa. }\end{array}$ & \\
\hline 13 & Art. 227 F. I & Abuso de confianza & $\begin{array}{l}\text { Perseguibles por querella, } \\
\text { punibilidad máxima que no } \\
\text { excede de tres años de prisión } \\
\text { y de noventa a doscientos } \\
\text { cincuenta días multa. }\end{array}$ & \\
\hline 14 & Art. 227 F. II & Abuso de confianza & $\begin{array}{l}\text { Perseguibles por querella } \\
\text { punibilidad máxima que no } \\
\text { excede de tres años de prisión } \\
\text { y de noventa a doscientos } \\
\text { cincuenta días multa. }\end{array}$ & \\
\hline 15 & Art. 230 F. I & Fraude & $\begin{array}{c}\text { Perseguibles por querella } \\
\text { y veinticinco a setenta y cinco } \\
\text { días multa. }\end{array}$ & $\begin{array}{c}\text { Cuando el valor de lo defraudado } \\
\text { no exceda de cincuenta veces la } \\
\text { unidad de cuenta de la Ciudad de } \\
\text { México vigente. }\end{array}$ \\
\hline 16 & Art. 230 F. II & Fraude & $\begin{array}{l}\text { Perseguibles por querella, } \\
\text { punibilidad máxima no excede de } \\
\text { tres años de prisión y de setenta y } \\
\text { cinco a doscientos días multa. }\end{array}$ & $\begin{array}{l}\text { Cuando el valor de lo defraudado } \\
\text { exceda de cincuenta pero no } \\
\text { de quinientas veces la Unidad de } \\
\text { Cuenta de la Ciudad de México } \\
\text { vigente. }\end{array}$ \\
\hline 17 & $\begin{array}{l}\text { Art. } 232 \\
\text { (hipótesis perjuicio } \\
\text { patrimonial) }\end{array}$ & Fraude & $\begin{array}{l}\text { Perseguibles por querella, } \\
\text { punibilidad máxima no excede de } \\
\text { tres años de prisión y de setenta y } \\
\text { cinco a doscientos días multa. }\end{array}$ & \\
\hline 18 & Art. 234 & $\begin{array}{l}\text { Administración } \\
\text { fraudulenta }\end{array}$ & $\begin{array}{l}\text { Perseguibles por querella, } \\
\text { veinticinco a setenta y cinco } \\
\text { días multa. } \\
\text { Perseguibles por querella, } \\
\text { punibilidad máxima no excede de } \\
\text { tres años de prisión y de setenta y } \\
\text { cinco a doscientos días multa. }\end{array}$ & $\begin{array}{l}\text { Se aplican las penas de fraude } \\
\text { artículo } 230 \text { fracciones I o II. }\end{array}$ \\
\hline 19 & Art. 239 F. I & $\begin{array}{c}\text { Daño a } \\
\text { la propiedad }\end{array}$ & $\begin{array}{c}\text { Perseguibles por querella } \\
\text { y de veinte a sesenta días multa. }\end{array}$ & $\begin{array}{c}\text { Cuando el valor del daño no } \\
\text { exceda de veinte veces la Unidad } \\
\text { de Cuenta de la Ciudad de México } \\
\text { vigente. }\end{array}$ \\
\hline
\end{tabular}




\begin{tabular}{|c|c|c|c|c|}
\hline 20 & Art. 239 F. II & $\begin{array}{c}\text { Daño a } \\
\text { la propiedad }\end{array}$ & $\begin{array}{c}\text { Perseguibles por querella, } \\
\text { punibilidad máxima no excede } \\
\text { de tres años de prisión y sesenta a } \\
\text { ciento cincuenta días multa. }\end{array}$ & $\begin{array}{l}\text { Cuando el valor del daño exceda } \\
\text { de veinte pero no de trescientas } \\
\text { veces la Unidad de Cuenta de la } \\
\text { Ciudad de México vigente. }\end{array}$ \\
\hline 21 & Art. 239 F. III & $\begin{array}{c}\text { Daño a } \\
\text { la propiedad }\end{array}$ & $\begin{array}{c}\text { Perseguibles por querella, } \\
\text { punibilidad máxima no excede } \\
\text { de tres años de prisión y de ciento } \\
\text { cincuenta a cuatrocientos días } \\
\text { multa. }\end{array}$ & $\begin{array}{c}\text { Cuando el valor del daño exceda } \\
\text { de trescientos pero no de setecien- } \\
\text { tas cincuenta veces la Unidad } \\
\text { de Cuenta de la Ciudad de México } \\
\text { vigente. }\end{array}$ \\
\hline
\end{tabular}

Fuente: Elaboración propia.

Por su parte, en relación al proceso constitucional de amparo en la vía directa se advierte que "es improcedente contra la resolución del Juez de Control que no admite a trámite la acción penal privada al no ser una determinación con la que se ponga fin al juicio"; ${ }^{15}$ por lo que hace a la vía indirecta Eduardo López Betancourt, dice que procederá "contra actos de los tribunales de justicia penal realizados fuera de juicio, por ejemplo: antes del juicio, durante la etapa de investigación, las autorizaciones judiciales que permiten actos de investigación, la no admisión de la acción penal privada; o después de concluido, como las decisiones de los jueces de ejecución", ${ }^{16}$ advirtiendo que si bien es cierto que el particular no podrá volver a intentar el EAPP por los mismos hechos en caso de no ser admitida, también lo es que nada le impide acudir a sede ministerial a querellarse y así iniciar carpeta de investigación, por virtud de lo establecido

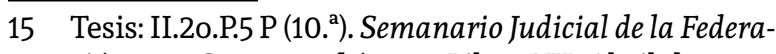
ción y su Gaceta. 10. ${ }^{a}$ época. Libro VII. Abril de 2012. Tomo 2, p. 1680.

16 López Betancourt, Eduardo. Amparo en materia penal. IURE. México, 2018, p. 132. en el artículo 431 párrafo $2 .^{\circ}$ del CNPP, que dispone: "De no subsanarse o de ser improcedente su pretensión, se tendrá por no interpuesta la acción penal y no podrá volver a ejercerse por parte del particular por esos mismos hechos”. Es decir, a través de una interpretación integral de la norma, el texto prohíbe el EAPP por similitud de circunstancias fácticas, siendo omiso respecto de la perfección que pudiere actualizarse con posterioridad al pronunciamiento del Juez y en consecuencia querellarse ante el AMP.

Por lo que hace al EAPP, el artículo 431 del CNPP establece que el Juez de Control constatará que los requisitos formales y materiales se tengan por satisfechos o no, en esta última hipótesis prevendrá al particular para que en el uso de la voz subsane dichos requisitos, de no poder satisfacer la prevención, tendrá un plazo de tres días para subsanarlos, en caso de no hacerlo dicha acción quedará sin efectos teniéndola por no interpuesta y no podrá volver a ejercerse por particular por esos mismo hechos, ahora bien, de ser admitido el EAPP, el Juez de Control ordenará la 
citación del imputado, apercibido, que de no acudir, se ordenará su comparecencia o aprehensión, según proceda, teniendo como plazos los siguientes: 48 horas antes de la audiencia inicial, misma que se celebrará dentro de los 5 a 10 días siguientes a aquel en que fue admita la acción penal por particular, informándole al imputado que tiene derecho a un abogado de su elección y en caso de no tener, se le impondrá uno del Estado.

Cabe destacar que el particular no podrá acudir ante el AMP para solicitar el ius puniendi del Estado previo a acudir ante el Juez de Control, además que la responsabilidad de acreditar el hecho que la ley señala como delito recaerá en el particular, por otro lado de cumplir con los requisitos de ley, se atenderá a lo conducente al proceso ordinario, así mismo se privilegiará la solución del conflicto mediante los mecanismos alternativos de solución de controversias.

\section{V. ¿El EAPP es un derecho humano?}

Con fundamento en el artículo 335 del CNPP, el ejercicio de la acción penal se encuentra supeditado a la conclusión de la fase de investigación complementaria, así como de la pertinencia, idoneidad y suficiencia de los medios de prueba recabados para que el AMP estime procedente ejercer acción penal, o en su caso solicite el sobreseimiento del asunto; en este orden, dicho ejercicio se verá materializado con un escrito de acusación, propio de la etapa intermedia, en donde se verificarán dichos elementos suasorios que el AMP pretenda incorporar a juicio, por lo que en una fase oral de la etapa intermedia estos se depurarán en la fase de exclusión probatoria. Es decir, el poder punitivo del Estado se actualiza -por así hacer mencióncon efectos formales hasta dicha etapa, por otro lado se advierte en el artículo 211 el inicio del ejercicio de la acción, mismo que "inicia con la solicitud de citatorio a audiencia inicial, puesta a disposición del detenido ante la autoridad judicial o cuando se solicita la orden de aprehensión o comparecencia”, luego, el ejercicio de la acción, resulta tener efectos jurídicos por lo que hace a la continuidad del proceso ordinario. En este tenor, estamos ante una segunda fase en el EAPP, es decir, en el supuesto que la solicitud haya sido procedente, se citará al imputado para que comparezca ante Juez de Control, lo que comúnmente en la praxis se le denomina "judicialización”.

Se invocó anteriormente el artículo 21 párrafo $2 .^{\circ}$ constitucional, mismo que faculta al particular a ejercer acción penal, remitiendo a la ley adjetiva para efecto de la debida substanciación. Ahora bien, los derechos humanos, como prerrogativas inalienables de las personas, son aquellos que pretenden proteger la dignidad de estas desde antes de su nacimiento, e incluso después de su muerte, en este tenor, en la actualidad la Constitución Política de los 
Estados Unidos Mexicanos y los Tratados Internacionales reconocen derechos humanos, logrando un espectro maximizado de regulación jurídica en protección de la dignidad de las personas, ello obligando a todas las autoridades en el ámbito de sus competencias a promover, respetar, proteger y garantizar los derechos humanos, mismos que como conjunto, forman parte de un control de parámetros de regularidad, bajo los principios pro persona e interpretación conforme, teniendo en consecuencia un escrutinio integral y por tanto, protección jurídica maximizada.

Ahora bien, atendiendo a que el EAPP tiene un sujeto obligado (Juez de Control) que resolverá sobre la controversia velando por los derechos de las partes, además se encuentra regulado en la Constitución Federal, actualizándose el acceso a la justicia a las víctimas, el EAPP es un derecho humano de doble fuente, que además, en términos de Alberto del Castillo del Valle "cuando el derecho humano se resguarda frente a la autoridad pública o estatal, nace la garantía del gobernado (que es la vía jurídica que protege ese derecho frente a la autoridad pública, sin la cual no surge la obligación estatal de respetar el mismo)". Es decir, el EAPP es un derecho humano (garantía) que funciona como mecanismo jurídico para que las víctimas sometan a escrutinio una controversia y que esta se resuelva a nivel institucional.

\section{Derecho comparado}

"Para entender un fenómeno es útil comparar" ${ }^{17}$ Bajo la premisa anterior, se desprende que legislaciones en un contexto sociojurídico parecidos al nuestro cuentan con la institución procesal que nos ocupa, por lo cual, es importante citar dichas legislaciones con la finalidad de contrastarlas con el plano nacional. No omitiendo mencionar que en dicho contexto, previo a la entrada en vigor del CNPP existieron diversos instrumentos procesales acusatorios en México, y al menos ocho entidades federativas contemplaban la procedencia del EAPP.

17 Christie, Nils. Una sensata cantidad de delito, op. cit., p. 42. 
Tabla 2. Legislaciones de países con sistemas sociojurídicos parecidos al mexicano

\section{Legislaciones de países con sistemas sociojurídicos parecidos al mexicano}

\begin{tabular}{|c|c|c|c|}
\hline Núm. & País & Norma & Delitos \\
\hline 1 & Argentina & $\begin{array}{l}\text { Código Penal de la Nación } \\
\text { Argentina, artículo, } \\
\text { Ley } 11.179 . \\
\text { Artículo } 73\end{array}$ & $\begin{array}{l}\text { Calumnias e injurias; violación de secretos, salvo } \\
\text { en los casos de los artículos } 154 \text { y 157; concurrencia } \\
\text { desleal, prevista en el artículo 159; incumplimiento } \\
\text { de los deberes de asistencia familiar, cuando la } \\
\text { víctima fuere el cónyuge. }\end{array}$ \\
\hline 2 & Bolivia & $\begin{array}{l}\text { Código de Procedimientos } \\
\text { Penales. } \\
\text { Artículo } 20\end{array}$ & $\begin{array}{l}\text { El giro de cheque en descubierto, giro defectuoso } \\
\text { de cheque, desvío de clientela, corrupción } \\
\text { de dependientes, apropiación indebida, abuso } \\
\text { de confianza, los delitos contra el honor, destrucción } \\
\text { de cosas propias para defraudar, defraudación } \\
\text { de servicios o alimentos, alzamiento de bienes } \\
\text { o falencia civil, despojo, alteración de linderos, } \\
\text { perturbación de posesión, daño simple e insultos } \\
\text { y otras agresiones verbales por motivos racistas } \\
\text { o discriminatorios. }\end{array}$ \\
\hline 3 & Chile & $\begin{array}{l}\text { Código Procesal Penal. } \\
\text { Artículo } 55\end{array}$ & $\begin{array}{l}\text { La calumnia y la injuria; la falta descrita en el número } \\
11 \text { del artículo } 496 \text { del Código Penal; la provocación a } \\
\text { duelo y el denuesto o descrédito público por no haberlo } \\
\text { aceptado; el matrimonio del menor llevado a efecto sin } \\
\text { el consentimiento de las personas designadas por la } \\
\text { ley y celebrado de acuerdo con el funcionario llamado } \\
\text { a autorizarlo. }\end{array}$ \\
\hline 4 & Ecuador & $\begin{array}{l}\text { Código de Procedimientos } \\
\text { Penales. } \\
\text { Artículo } 36\end{array}$ & $\begin{array}{l}\text { El estupro perpetrado en una persona mayor de } \\
\text { dieciséis años y menor de dieciocho; el rapto de una } \\
\text { mujer mayor de dieciséis años y menor de dieciocho, } \\
\text { que hubiese consentido en su rapto y seguido volun- } \\
\text { tariamente al raptor; la injuria calumniosa y la no } \\
\text { calumniosa grave; los daños ocasionados en propiedad } \\
\text { privada, excepto el incendio; la usurpación; la muerte } \\
\text { de animales domésticos o domesticados. }\end{array}$ \\
\hline 5 & Paraguay & $\begin{array}{l}\text { Código Procesal Penal. } \\
\text { Artículo } 17\end{array}$ & $\begin{array}{l}\text { Maltrato físico; lesión; lesión culposa; amenaza; } \\
\text { tratamiento médico sin consentimiento; violación de } \\
\text { domicilio; lesión a la intimidad; violación del secreto } \\
\text { de comunicación; calumnia; difamación; injuria; } \\
\text { denigración de la memoria de un muerto; daño; uso } \\
\text { no autorizado de vehículo automotor; y violación del } \\
\text { derecho de autor o inventor. }\end{array}$ \\
\hline 6 & Nicaragua & $\begin{array}{l}\text { Código Procesal Penal de } \\
\text { la República de Nicaragua. } \\
\text { Artículo } 53\end{array}$ & Calumnia e injurias graves. \\
\hline
\end{tabular}




\begin{tabular}{|c|c|c|c|}
\hline 7 & República Dominicana & $\begin{array}{l}\text { Código Procesal Penal de } \\
\text { la República Dominicana. } \\
\text { Artículo } 32\end{array}$ & $\begin{array}{l}\text { Violación de propiedad; difamación e injuria; } \\
\text { violación de la propiedad industrial, con excepción } \\
\text { de lo relativo a las violaciones al derecho de marcas, } \\
\text { que podrán ser perseguibles por acción privada } \\
\text { o por acción pública; violación a la Ley de Cheque. }\end{array}$ \\
\hline 8 & Salvador & $\begin{array}{l}\text { Código Procesal Penal. } \\
\text { Artículo } 28\end{array}$ & $\begin{array}{l}\text { Los relativos al honor y a la intimidad; hurto impropio; } \\
\text { competencia desleal y desviación fraudulenta de clien- } \\
\text { tela; y, cheques sin provisión de fondos. }\end{array}$ \\
\hline 9 & Costa Rica & $\begin{array}{l}\text { Código Procesal Penal. } \\
\text { Artículo } 19\end{array}$ & $\begin{array}{l}\text { Los delitos contra el honor; la propaganda desleal; } \\
\text { cualquier otro delito que la ley califique como tal. }\end{array}$ \\
\hline
\end{tabular}

Fuente: Elaboración propia.

Derivado de lo anterior, después de una búsqueda exhaustiva en países con sistemas sociojurídicos parecidos al nuestro, no se encontró información relativa al EAPP que nos aporte estadística, operatividad, infortunios o asuntos exitosos que nos permita comparar o en su caso, proponer una postura a manera de iniciativa legislativa que pudiere ser aplicable al marco jurídico nacional, en este orden, se intuye que la institución que nos ocupa no es explotada ni potencializada en la práctica, obedeciendo -probablemente- a la propia configuración normativa, a falta de capacitación y/o a falta de socialización, pues la ausencia de información bien se puede traducir en que los resultados aportados no son significativos.

Por lo que hace al contexto nacional, la suerte del EAPP no cambia mucho en relación con los Estados antes mencionados, no omitiendo que existen pocas investigaciones serias del EAPP, en comparación con otras figuras del modelo procesal penal acusatorio. Es así que el Estado mexicano, a 12 años de la reforma procesal penal y a 4 años de su implementación total a nivel nacional, no se ha pronunciado suficientemente mediante informe oficial, advirtiendo casos exitosos, infortunios, reformas o promoción del EAPP, salvo dos tesis aisladas previamente mencionadas, foros académicos y escasa promoción, por ejemplo, el Estado de México ${ }^{18}$ y el Distrito Federal (ahora Ciudad de México), ${ }^{19}$ basándose en un contexto explicativo a manera de investigación jurídica, sin realmente hacer una difusión para toda la sociedad y que esta la comprenda.

18 Cfr. Acción Penal Privada. Procuraduría General de Justicia del Estado de México. https://fgjem.edomex.gob.mx/sites/fgjem.edomex.gob.mx/files/files/ Acercade/accion\%20penal\%20privada.pdf

19 Cfr. Análisis de la figura del ejercicio de la acción penal privada. Instituto de Formación Profesional. http://www.poderjudicial-gto.gob.mx/pdfs/P9.pdf 
A mayor abundamiento, y derivado de mi interés académico por el tema, realicé una solicitud de información pública en la Plataforma Nacional de Transparencia, la Dirección de Estadística de la Presidencia del Tribunal Superior de Justicia de la Ciudad de México, quien proporcionó la siguiente información:

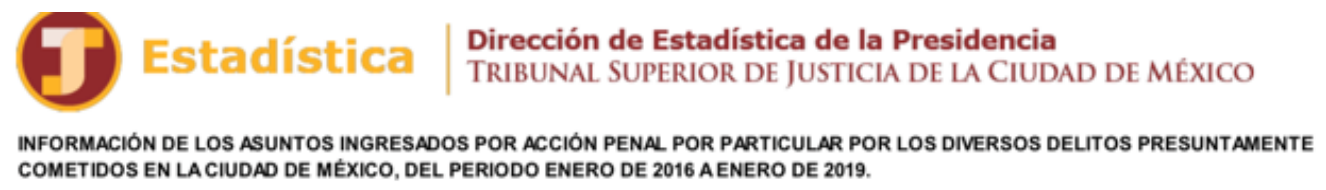

\begin{tabular}{|c|c|c|c|c|c|c|c|}
\hline Materia & $\begin{array}{l}\text { Indice para } \\
\text { Agrupación } 1\end{array}$ & $\begin{array}{c}\text { Indice para } \\
\text { Agrupación } 2\end{array}$ & $\begin{array}{l}\text { Año } \\
\text { ingreso }\end{array}$ & $\begin{array}{c}\text { Mes } \\
\text { ingreso }\end{array}$ & Tipo Delictivo & $\begin{array}{c}\text { Desagregado de interes } \\
\text { estadistico }\end{array}$ & $\begin{array}{l}\text { Alcaldia de } \\
\text { ocurrencia } \\
\text { del delito }\end{array}$ \\
\hline Sistema Procesal Penal Acusatorio & 44354442002992 & 48972 & 2016 & 1 & Fraude & SINC & Coyoacán \\
\hline Sistema Procesal Penal Acusatorio & 44354442002992 & 48994 & 2016 & 1 & Fraude & $\operatorname{sinc}$ & Coyoacán \\
\hline Sistema Procesal Penal Acusatorio & 44354442002992 & 49016 & 2016 & 1 & Fraude & $\operatorname{sinc}$ & Coyoacán \\
\hline Sistema Procesal Penal Acusatorio & 44354442018480 & 80674 & 2016 & 4 & Abuso de confianza & $\sin C$ & No especificada \\
\hline Sistema Procesal Penal Acusatorio & 44354442019030 & 81840 & 2016 & 4 & Despojo & Despojo de inmueble ajeno & No especificada \\
\hline Sistema Procesal Penal Acusatorio & 44354442019030 & 81862 & 2016 & 4 & Despojo & Despojo de inmueble ajeno & No especificada \\
\hline Sistema Procesal Penal Acusatorio & 44354442087692 & 240086 & 2016 & 10 & Incumplimiento de la obligacion alim & $\operatorname{sinc}$ & No especificada \\
\hline Sistema Procesal Penal Acusatorio & 44376442165594 & 781044 & 2017 & s & Abuso de confianza & $\operatorname{sinC}$ & No especificada \\
\hline Sistema Procesal Penal Acusatorio & 44398442101684 & 1850178 & 2018 & 2 & Daño a la propiedad & Otros & No especificada \\
\hline Sistema Procesal Penal Acusatorio & 44398442150986 & 1990472 & 2018 & 3 & Fraude & SINC & No especificada \\
\hline Sistema Procesal Penal Acusatorio & 44398442374242 & 2631376 & 2018 & 7 & Fraude & $\operatorname{sinC}$ & No especificada \\
\hline Sistema procesal Penal Acusatorio & 44354442002442 & 47740 & 2016 & 1 & Robo & Otos & Miguel Hidalgo \\
\hline Sistema procesal Penal Acusatorio & 44376442191246 & 864094 & 2017 & 6 & Fraude & $\operatorname{sinc}$ & No especificada \\
\hline Sistema Procesal Penal Acusatorio & 44354442004070 & 51172 & 2016 & 1 & Despojo & Despojo de inmueble sjeno & iztacalco \\
\hline Sistema Procesal Penal Axusatorio & 44354442004510 & $\$ 2074$ & 2016 & 1 & Fraude & $\sin C$ & No especificado \\
\hline Sistema Procesal Penal Acusatorio & 44354442004510 & $\$ 2096$ & 2016 & 1 & Fraude & $\operatorname{sinC}$ & No especificado \\
\hline Sistema Procesal Penal Acusatorio & 44354442004510 & $\$ 2118$ & 2016 & 1 & Fraude & $\operatorname{sinC}$ & No especificado \\
\hline Sistema Procesal Penal Acusatorio & 44354442017996 & 79640 & 16 & 4 & Violencia familiar & $\operatorname{sinC}$ & No especificada \\
\hline Sistema Procesal Penal Azusatorio & 44354442018348 & 80388 & 16 & 4 & Fraude contra un establecimiento con & sinc & No especificada \\
\hline Sistema Procesal Penal Azusatorio & 44354442017468 & 78496 & 016 & 4 & Violencia familiar & SINC & No especificada \\
\hline Sistema Procesal Penal Azusatorio & 44354442017600 & 78760 & 2016 & 4 & Violencia tamiliar & $\operatorname{sinC}$ & No especificada \\
\hline Sistema Procesal Penal Azusatorio & 44376442172810 & 805244 & 2017 & 6 & Robo & Robo de objetos & No especificada \\
\hline Sistema Procesal Penal Axusatorio & 44376442172810 & 805266 & 2017 & 6 & Robo & Robo de objetor & No especificada \\
\hline Sistema Procesal Penal Axusatorio & 44398442148346 & 1982222 & 2018 & 3 & Lesiones & Lesiones por golpes & No especificada \\
\hline Sistema Procesal Penal Axusatorio & 44354442042790 & 133056 & 2016 & 7 & Privacion de la libertad personal & $\operatorname{sinc}$ & No especificada \\
\hline Sistema Procesal Penal A<usatorio & 44398442465652 & 2916122 & 2018 & 9 & Falsedad ante autoridades & Falsedad ante autoridades, MP m & INo especificada \\
\hline Sistemu Procesal Penal Acusatorio & 44398442465652 & 2916144 & 2018 & 9 & Falsedad ante autoridades & Falsedad ante autoridades, MP min & t No especificada \\
\hline
\end{tabular}

Notas:

1. El "hdice para Agrupacion $1^{2}$ es un valor generado para hacer agrupaciones de cardctor estadissco, por cada asuno ingresado que en ningùn caso se vincula con el nùmero de expedientecarpeta reil

2. El "holice para Agrupacion $2^{2}$ es un valor generado para hacer agrupaciones de caracter estadistico, que hace referencia a cada persona de los asuntos ingresados y que en ningùn caso se vincula con los nombres reales de las personas.

3. La información es ta desagregada por asunto, personas en los asuntos ydelitos cométios por las personas en los asuntos.

4. Un asunto ingresado se identíca con un "hdice para Agrupación 1 "único. Si el "hdice para Agrupación 1 " se repile, significa que el asumb tene más de una persona asociada al mismo.

5. Una persona se identica con un "Indice para Agrupacion 2 " unico. Si el "Indice para Agrupacion 2 " se repite, significa que sene más de un delito asociado.

Fuente: Dirección de Estadisfica de la Presidencia con información de las unidades de gestión judicial.

\section{Matriz 1. Estadística del EAPP}

De acuerdo con la información recabada, los delitos de violencia familiar, incumplimiento de obligación alimentaria, despojo, privación de la libertad personal, y falsedad ante autoridades, no podrían ser susceptibles del EAPP en razón que la punibilidad es mayor a tres años, pese a que la autoridad jurisdiccional proporcionó información en tal sentido; por otro lado, el delito de privación de la libertad personal, por exclusión, no requiere el requisito de procedibilidad de querella, por virtud de que la ley sustantiva no lo establece, luego entonces, es perseguible de oficio, por lo que tampoco entraría en los supuestos legales del EAPP. 
Lo anterior es preocupante, puesto que se actualizó un infortunio procesal en atención al desconocimiento o descuido de la procedencia del EAPP y en el supuesto de haber sido admitido, se vería mancillado el debido proceso en perjuicio de las partes y en todo caso, del sistema procesal penal acusatorio, o bien la información suministrada contiene errores graves en su compilación. Ahora bien, 27 asuntos fueron ingresados, de los cuales por lo menos 17 serían procedentes de cumplir con los requisitos de ley, es así que en el año 2016 se ingresaron 17 EAPP de los cuales 9 serían procedentes y 8 no procedentes; para el año 2017 se ingresaron 4, en el año 2018 se ingresaron 6, de los cuales solo 4 de ellos serían procedentes y por último, para el mes de enero de 2019 no hubo ingresos.

En este contexto, si tomamos en cuenta la incidencia delictiva en la Ciudad de México, la Encuesta Nacional de Victimización y Percepción sobre Seguridad Pública (ENVIPE) 2019, ${ }^{20}$ dice lo siguiente:

20 Cfr. Instituto Nacional de Estadística y Geografía. Encuesta Nacional de Victimización y Percepción sobre Seguridad Pública (ENVIPE) 2019. https:// www.inegi.org.mx/programas/envipe/2019/

Tabla 3. Delitos ocurridos para la Ciudad de México por tipo de delito, según cifra negra

\begin{tabular}{|c|c|c|c|}
\hline & \multirow[b]{2}{*}{ Delitos ocurridos } & \multicolumn{2}{|c|}{ Cifra negra } \\
\hline & & Absolutos & Relativos \\
\hline Ciudad de México & 4830779 & 4542586 & 94.0 \\
\hline Robo total de vehículo & 60600 & 23896 & 39.4 \\
\hline Robo parcial de vehículo & 518237 & 485048 & 93.6 \\
\hline Robo en casa habitación & 140537 & 122969 & 87.5 \\
\hline Robo o asalto en calle o transporte público & 2151172 & 2062860 & 95.9 \\
\hline Robo en forma distinta a las anteriores & 96462 & 89687 & 93.0 \\
\hline Fraude & 702139 & 648289 & 92.3 \\
\hline Extorsión & 456468 & 443100 & 97.1 \\
\hline Amenazas verbales & 264978 & 241573 & 91.2 \\
\hline Lesiones & 140207 & 132679 & 94.6 \\
\hline Otros delitos distintos a los anteriores & 299979 & 292485 & 97.5 \\
\hline
\end{tabular}

Fuente: Elaboración propia. 
Tabla 4. Delitos ocurridos para la Ciudad de México por región, según cifra negra

\begin{tabular}{|c|c|c|c|}
\hline \multirow[b]{2}{*}{ Región } & \multirow[b]{2}{*}{ Delitos ocurridos } & \multicolumn{2}{|c|}{ Cifra negra } \\
\hline & & Absolutos & Relativos \\
\hline Estados Unidos Mexicanos & 33035090 & 30801091 & 93.2 \\
\hline Ciudad de México & 4830779 & 4542586 & 94.0 \\
\hline Región Norte & 1028355 & 953251 & 92.7 \\
\hline Región Sur & 784891 & 723098 & 92.1 \\
\hline Región Oriente & 1284216 & 1233293 & 96.0 \\
\hline Región Poniente & 1625048 & 1528450 & 94.1 \\
\hline
\end{tabular}

Fuente: Elaboración propia.

De las tablas anteriores, se desprende que en el año 2018 se denunció solamente el 7 $\%$ de los delitos ocurridos a nivel nacional y en la Ciudad de México el $6.3 \%$, es así que respecto del EAPP, partiendo de la estadística del Tribunal Superior de Justicia de la Ciudad de México en comparación con la Encuesta Nacional de Victimización y Percepción sobre Seguridad Pública (ENVIPE) de los años 2017, 2018 y 2019 se verifica la siguiente información estadística: de los delitos ingresados en 2016 y que son jurídicamente procedentes para el EAPP, corresponde tan solo al $0.0042 \%$, para 2017 el $0.0012 \%$, para el 2018 el $0.0013 \%$ y para el 2019, respecto del mes de enero no hubo ingresos y además no se ha reportado información oficial. Con relación al año 2018 y tomando en consideración el porcentaje de delitos denunciados en Ciudad de México, el delito de fraude corresponde al $1.1 \%$, amenazas al $0.48 \%$, lesiones $0.15 \%$, robo $0.14 \%$, incidencia delictiva que en evidencia, merma el tejido social, en este tenor, los delitos del porcentaje anterior -de cum- plirse con los requisitos- son susceptibles del EAPP y de materializarse, reduciría de forma importante la carga de trabajo para el AMP, ahorrando recursos económicos y humanos. No omitiendo mencionar que el porcentaje de la cifra negra (delitos no denunciados) de todos los años referidos, se encuentra por encima del $90 \%$, cifra que en gran medida, representa impunidad por factores diversos, siendo los principales la falta de confianza en la procuración de justicia y falta de recursos.

En este orden de ideas, es abrumadora la cifra de delitos que ocurrieron en 2018 en la Ciudad de México, prevaleciendo los delitos de robo, fraude, lesiones y amenazas, tipos penales que de acreditarse debidamente serían susceptibles del EAPP y por ende una posible vía procesal para solucionar el conflicto, en pro de las partes y de la procuración de justicia, liberando cargas de trabajo a los operadores del sistema.

Respecto de los foros académicos, Alberto Nava dice que "si bien la reforma constitucional de 2008 instauró la figura 
de la acción penal promovida por un particular, la realidad es que esta no tiene relevancia en el Sistema Penal Mexicano y los casos en las que ha sido usada con éxito son muy pocos", ${ }^{21}$ lo que se traduce en una falta de interés por parte del Estado para que los particulares ejerzan acción penal y conserve el poder punitivo, es decir, continuarse a sí mismo sobre los particulares obteniendo control y por ende, poder institucional, siendo que el EAPP es una institución simbólica que legitima el actuar de un sistema, actualizándose la tesis de Chul Han, en razón que "el actual sujeto de rendimiento es actor y víctima a la vez"22 al estar limitados en dicho ejercicio procesal, debido a la punibilidad tan baja y además por lo costoso que pudiera implicar contratar diversos servicios que permitan ejercer la acción, además que como se ha venido exponiendo, el accionante es la propia víctima "explotándose a sí mismo", ${ }^{23}$ es decir, la víctima se ve ante una hiperrealidad de un sistema que le concede poder punitivo, control ciudadano y transparencia; sin embargo, la propia naturaleza del Estado la priva de dicho control, regresando al mismo punto de partida, siendo el EAPP una ficción jurídica que le hace creer a la víctima que puede acceder a la justicia, envolviéndola en

21 Cfr. Gobierno de México. Instituto Nacional de Ciencias Penales (INACIPE). http://www.inacipe.gob. $\mathrm{mx} /$ comunicacion/articulos/accionpenal_arti.php

22 Chul Han, Byung, En el enjambre, op. cit., p. 31.

23 Cfr. Chul Han, Byung, En el enjambre, op. cit., 2019. trámites, abogados, servidores públicos con ganas de delegar trabajo y un cansancio sin límites que esclaviza a la víctima presionándola sin sentido, legitimando su participación mediante un institución procesal penal simbólica. Siguiendo con la cita del conferencista el hablar de que hay pocos casos exitosos es señal de una información existente que al menos no es pública, pero aportaría información relevante para saber la substanciación de la acción, resolución, estatus, tipos penales, entre otros.

\section{Derecho procesal penal simbólico}

"Los sistemas penales son indicadores del tipo de sociedad en que se vive. Los cambios en los sistemas penales se relacionan con los cambios dentro de una sociedad determinada". ${ }^{24}$ De acuerdo con lo anterior y en concordancia con don Raúl Zaffaroni, lo único verdadero es la realidad, es decir, una realidad de un sistema procesal penal acusatorio y un CNPP que contemplan una institución jurídica novedosa pero poco estudiada, con falta de interés por parte de los abogados en su uso, con un desconocimiento de dicha institución por parte de la población y que a 4 años de su entrada en vigor, no hay señales contundentes por parte del Estado en legislar o socializar en pro de las víctimas el EAPP, en contraposición, el Estado pro-

24 Christie, Nils. Una sensata cantidad de delito, op. cit., p. 99. 
mete un cambio de paradigma con mayor participación por parte de las víctimas, sin embargo, dicho cambio no se actualiza, por lo menos con el EAPP, resultando las siguientes interrogantes: ¿En qué tipo de sociedad vivimos?, a más de diez años de la reforma procesal penal, ¿qué sistema acusatorio prevalece en México?, ¿qué víctimas acceden al EAPP? Interrogantes que con base en la presente investigación aportan las siguientes aproximaciones: la sociedad en la que vivimos es tal que se ve abrumada por la delincuencia, además que desconoce o no tiene interés por el EAPP; un sistema procesal en donde si bien denota una clara intención de participación en relación a la víctima, también lo es que se actualiza -y no de forma imprevista- una sociedad incrédula ante el sistema procesal penal, un EAPP con requisitos que implican un gasto económico que probablemente es mayor del que se vería en algún momento reparado en razón de la naturaleza de los requisitos de ley, un EAPP desaprovechado y un Estado desinteresado en la promoción a la que está obligado para que las víctimas conozcan dicha institución, por ende tampoco los mecanismos para el acceso informado a el EAPP; por lo que hace a la víctima, sería obvio partir de la idea que la víctima poderosa a contrario sensu de la que no tiene los recursos suficientes para contratar los servicios de un abogado, aprovechara dicha institución, sin descartar que cual- quier víctima podría acudir con la autoridad para que esta le designare un asesor jurídico que la represente en el EAPP, gestión que no se encuentra prevista en la ley, por ende tampoco es prohibida. Luego, desde un punto de vista spensoriano (racista) el EAPP al tener escasa legislación de punibilidad, promoción insuficiente y un sistema acusatorio despreocupado de tal situación dará paso a que las víctimas con pocos recursos no denuncien y que se advierta impunidad, luego entonces, que estas culminen por vengar de mano propia sus intereses (pobres contra pobres), sirviéndose el Estado de una institución procesal penal simbólica para legitimar la participación de la víctima.

Girard es terminante al considerar que "el poder punitivo formalizado en la civilización actual tiene por función canalizar racionalmente la venganza", ${ }^{25}$ es decir, un Estado que mediante un Poder Judicial independiente e imparcial, administre justicia (venganza), siendo el EAPP una forma racionalizadora de la venganza, propia de un sistema democrático, en donde la víctima participe encontrando una solución que evite la violencia y así esta, acceda a la justicia como un símil de venganza, viéndose reparada en su esfera jurídica, sin embargo, actualmente esto no sucede, como lo hemos visto anteriormente, los números advierten una realidad diversa a

25 Zaffaroni, Eugenio Raúl. La cuestión criminal. Planeta. Buenos Aires, 2010, p. 213. 
los propósitos del legislador, luego entonces, el EAPP es una utopía procesal penal.

Robert Merton distingue entre funciones manifiestas y latentes, "las primeras relativas a las consecuencias objetivas para una unidad especificada (persona, subgrupo, sistema social o estructural) que contribuyen a su ajuste o adaptación y se esperan así; las segundas relativas a las consecuencias inesperadas y no reconocidas del mismo orden". ${ }^{26}$ Luego entonces, en un esfuerzo por plasmar mediante una finalidad jurídica heurística dichos conceptos se plantea que las funciones manifiestas son las intenciones que el legislador espera que se materialicen y/o lleven a cabo, ello en consideración a las exigencias sociales de justicia de los ciudadanos, intenciones que a la letra son verdaderos poemas utópicos para el lector, siendo que en apariencia resultan ser un discurso falaz que no se ajusta a las necesidades propias de una sociedad abrumada por la delincuencia y carente de recursos; por su parte las funciones latentes son aquellas que se materializan realmente, funciones que evidencian la ausencia de una base jurídicosocial sólida, generando desinformación, incertidumbre jurídica y la sensación de encubrimiento de una situación fáctica mediante el ya mencionado discurso falaz. Ej.: La exposición de motivos de la reforma de 2008 dice lo siguiente:

26 Merton, Robert. Teoría y estructuras sociales. Fondo de Cultura Económica. México, 1992, pp. 138-139.
Respecto de este ejercicio de la acción penal por parte de los particulares, se prevén dos modalidades: la primera relativa a la posibilidad de que se adhiera a la acusación del Ministerio Público, la cual ya fue explicada al abordar el tema de la intervención en juicio, y la segunda, a través del ejercicio autónomo de esa facultad para determinados casos previstos en la ley. El ejercicio de la acción penal en estos supuestos será evidentemente excepcional, solo en aquellos casos en los que el interés afectado no sea general. Al igual que en el caso de la coadyuvancia, esta posibilidad no debe traducirse en que el Ministerio Público desatienda los casos, en virtud de que este deberá tener la intervención que ya de por sí le confiere el artículo 21. Tales posibilidades permitirán hacer más transparente la procuración y la administración de justicia, toda vez que se da pauta para la existencia de un control ciudadano sobre las funciones de procuración de justicia. ${ }^{27}$

Por otro lado, respecto de la funciones latentes, por lo que respecta al EAPP no ha generado "más" transparencia en la procuración de justicia, los requisitos son

27 Cfr. Secretaría de servicios parlamentarios centro de documentación, información y análisis dirección de bibliotecas y de los sistemas de información. http://www.diputados.gob.mx/sedia/biblio/ archivo/SAD-07-08.pdf 
un obstáculo verdaderamente complejo y la víctima no es del todo autónoma, luego entonces, el EAPP es una institución desaprovechada por los particulares, sin iniciativas de acción por parte del Estado para impulsar una mayor regulación de punibilidad para el ejercicio; un ejemplo de acción sería que el propio Estado mediante sus asesores jurídicos implementen protocolos de actuación y así resolver asuntos que liberen cargas de trabajo al AMP; o simplemente promover el EAPP, así como lo hacen con la justicia alternativa, vinculación a proceso, juicio y un gran etcétera. Luego, ¿será que de facto no le interese a nadie?, ¿ni a particulares y ni al Estado?

En este contexto, parecería que las funciones manifiestas reconocen derechos para que las víctimas participen activamente a lo largo del proceso, ejerciendo por sí, acción penal, procurando un acceso a la justicia; pero en realidad las funciones latentes evidencian que las funciones manifiestas son utópicas ya que no importa que obre en la legislación procesal penal una institución que dote de participación y por ende poder a los particulares en razón que la propia ley advierte requisitos someros con ánimo de que el particular no pueda acceder y de hacerlo, la intervención sea mínima, en donde además persiste la institución del AMP (Estado-AMP) que por supuesto, controlará todo, siendo realmente complicado que el particular controle la investigación; quedando el control ciudadano sobre la procuración de justicia en el papel, sí, otra vez...

Por su parte Eugenio Raúl Zaffaroni dice:

Como puede observarse, cada agencia tiene sus propios intereses sectoriales y sus propios controles de calidad de sus operaciones. Por ello, tienen discursos hacia fuera, que resaltan sus fines manifiestos (oficiales) más nobles (la seguridad y la decencia para la policía, la resocialización para los penitenciarios, los derechos para los jueces, la vocación de servicio para los políticos, el saber y la verdad para los académicos, la solidaridad internacional para las agencias de los países acreedores, el gobierno supranacional para los organismos internacionales, la información de los ciudadanos para la comunicación) y discursos hacia adentro, que justifican para sus miembros la disparidad entre sus fines manifiestos (oficiales) y lo que realmente hacen (fines latentes)" ${ }^{28}$

Por otro lado, derivado de un paternalismo estadual del cual nos servimos a conveniencia, Hegel en su "Dialéctica del amo y el esclavo" plantea que la relación entre el amo y el esclavo se basa en el reconocimiento mutuo, siendo que de ello depende la existencia misma del otro, es decir, el amo pondera la libertad y el es-

28 Zaffaroni, Eugenio Raúl. Manual de derecho penal parte general. EDIAR, 2006, p. 10. 
clavo la vida, por lo que el esclavo se ve sujeto a pervivir bajo el mando del amo, ya que el amo no es nadie sin esclavos, y estos requieren de ese mando, derivado de una obnubilación mental a la que se vieron condicionados desde el inicio de su existencia, es así que los asesores jurídicos están muy cómodos representando a las víctimas promoviendo querellas por escrito, siguiendo el curso de una investigación cansada, criticando el trabajo del AMP advirtiendo que ellos lo harían mejor, y en muchas ocasiones con escasas posibilidades de que los asuntos prosperen y de hacerlo, se pudiera actualizar la certeza jurídica del asunto en audiencia pública frente a un Juez de Control (ya pasado un largo tiempo...). En contraparte encontramos a las víctimas enfrentándose a un AMP que no les da la debida importancia y en muchos casos termina revictimizándolas, coexistiendo víctimas, asesores jurídicos y el AMP con un mando cuya excepción de no intervención es efímera.

De esta forma, "para que la norma pueda cumplir con su finalidad, esta debe poder ser operativa o funcional", ${ }^{29}$ es así que el EAPP no es eficaz y tampoco útil, derivado a que desatiende el "carácter instrumental de la norma” (que la víctima ejerza acción penal),,30 además que en el fondo dicha institución no advierte retribución eco-

29 Tanús Namnum, Virgilio. Tendencia actual de la política criminal. Tirant Lo Blanch, Ciudad de México, 2018, p. 87.

30 Ibídem, p. 65 nómica para los operadores, pero si una pérdida de recursos humanos, materiales y económicos para el Estado, sumado a ello, la poca participación de las víctimas y el desconocimiento y/o la falta de interés por parte de los abogados particulares o asesores jurídicos públicos, teniendo como consecuencia una política social de haberla- fracasada en razón que no atiende al control ciudadano sobre la procuración de justicia antes mencionado, tampoco a un cambio real en la sociedad para que las víctimas se vean reparadas en su esfera jurídica, resultando una formalidad esencial del proceso (acción penal por particular) ineficaz, actualizándose un Derecho procesal penal simbólico.

\section{Conclusiones}

Derivado del estudio, se sabe que la acción penal por particular tiene su origen teórico en el abolicionismo penal y su origen histórico en la venganza privada, seguida de una acción pública para tomar lugar administrando el ius puniendi y así racionalizar la venganza privada, en este sentido no quiere decir que al legislador se le hubiese olvidado la víctima, no, ahora el Estado limita la venganza racionalizándola mediante su imperium estatal.

A manera de conceptualización, el EAPP es un derecho humano de doble fuente, una garantía (en contrario sensu del AMP que como autoridad está facultada para ejercer acción penal), que funciona como 
un mecanismo en donde el particular está facultado para someter a escrutinio un asunto, del cual fue víctima ante una autoridad jurisdiccional ejerciendo acción penal, para que esta de forma independiente y neutral se pronuncie respecto de la admisión y en su momento del conflicto, lo anterior con fundamento en los artículos 1,17 párrafo 2. ${ }^{\circ}, 20$ apartado C, 21 párrafo 2. ${ }^{\circ}, 133$ de la Constitución Federal, 5. ${ }^{\circ}$ de la Declaración sobre los Principios Fundamentales de Justicia para las Víctimas de Delitos y del Abuso de Poder y 426 al 432, todos del CNPP; cabe destacar que en la ley no se ha actualiza algún concepto del EAPP.

De acuerdo con la procedencia, se actualizan 22 tipos penales en la Ciudad de México susceptibles al EAPP, en razón que se persiguen por querella, habiendo algunos cuya penalidad es alternativa, distinta a la privativa de libertad $u$ otros cuya punibilidad máxima no excede de tres años de prisión, en este orden, el EAPP no es eficaz, en razón que son muy pocos los delitos procedentes y en su mayoría con un alto índice de cifra negra, es decir, no son denunciados, por ende dicha institución no resulta de utilidad para la sociedad, luego, el acceso a la justicia queda condicionado a la pericia del operador jurídico que ejerza la acción, que de cumplir con los requisitos de ley se actualizaría la posibilidad de resolver de forma expedita el conflicto, siendo que en este supuesto, la relevancia opera por virtud de la certeza jurídica que el particular tendría, en razón al control judicial que de forma expedita se actualizó.

En atención a los datos estadísticos obtenidos, nos podemos percatar de lo desaprovechado que se encuentra el EAPP en la Ciudad de México, ya que para el 2016 corresponde tan solo al $0.0042 \%$, para 2017 al $0.0012 \%$, para el 2018 al $0.0013 \%$, y para el 2019 respecto del mes de enero no hubo ingresos y además no se ha reportado información oficial; lo anterior contraponiendo que en el año 2018 el porcentaje de delitos denunciados en la Ciudad de México fue tan solo del $6.3 \%$, aunado a que los porcentajes de los delitos de fraude corresponde al $1.1 \%$, amenazas al $0.48 \%$, lesiones $0.15 \%$ y robo $0.14 \%$, sumando $1.87 \%$ del $6.3 \%$, cifra sensata de delito, que bien podría liberar cargas de trabajo al AMP; sin embargo, habrá que considerar que muy probablemente el $1.87 \%$ se reduzca de forma considerable teniendo en cuenta que se deben cumplir con requisitos específicos de ley.

Por último, considerando los resultados estadísticos, información normativa y demás fuentes consultadas, se puede advertir que el EAPP es parte de la Expansión del Derecho procesal penal, como un derecho humano desaprovechado por las víctimas, ya que no hay afluencia en la participación de las mismas para ejercer acción penal; se advierte la omisión por parte de las instituciones en promover el EAPP, ya que si bien es cierto que es res- 
ponsabilidad del particular, también lo es que podría ir ante un asesor jurídico público y que este en consecuencia se haga cargo del asunto, sin embargo -insistono hay difusión al respecto; así las cosas, la institución jurídica del EAPP, resulta ineficaz y carente de posibilidades para acceder a la justicia ante un sistema procesal penal acusatorio.

\section{Bibliografía}

Libros

CHRISTIE, Nils. Una sensata cantidad de delito. Editores del Puerto. Buenos Aires, 2004.

CHUL HAN, Byung. Sobre el poder. Herder. España, 2016.

---- En el enjambre. Herder. Barcelona, 2019.

GIRARD, René. La violencia y lo sagrado, Anagrama. Barcelona, 1983.

LÓPEZ BETANCOURT, Eduardo. Amparo en materia penal. IURE. México, 2018.

MERTON, Robert. Teoría y estructuras sociales. Fondo de Cultura Económica. México, 1992. TANÚS NAMNUM, Virgilio. Tendencia actual de la política criminal. Tirant Lo Blanch. Ciudad de México, 2018.

TENORIO TAGLE, Fernando. El delito y el control del delito en la modernidad avanzada. $\mathrm{Pu}-$ blicia. Alemania, 2014.

ZAFFARONI, Eugenio Raúl. La cuestión criminal. Planeta. Buenos Aires, 2010.

--- Manual de derecho penal parte general. EDIAR, 2006.
ZAMORA GRANT, José. Derecho victimal, la víctima en el nuevo sistema penal mexicano. INACIPE. Ciudad de México, 2018.

--- La víctima en el proceso penal acusatorio. UNAM. México, 2014.

\section{Legislación}

CONSTITUCIÓN POLÍTICA DE LOS ESTADOS UNIDOS MEXICANOS. Última reforma publicada DOF 08-05-2020.

DECLARACIÓN SOBRE LOS PRINCIPIOS FUNDAMENTALES DE JUSTICIA PARA LAS VÍCTIMAS DE DELITOS Y DEL ABUSO DE PODER. Adoptada por la Asamblea General en su resolución 40/34, de 29 de noviembre de 1985.

CÓDIGO NACIONAL DE PROCEDIMIENTOS PENALES. Última reforma publicada DOF 22-01-2020.

CÓDIGO PENAL PARA EL DISTRITO FEDERAL. Última reforma publicada en la G.O.C.D.M.X., el 20 de marzo de 2020.

Tesis aisladas

Tesis: VI.1o.P.43 P (10. $\left.{ }^{a}\right)$. Gaceta del Semanario Judicial de la Federación. 10. ${ }^{a}$ época. Libro 53. Abril de 2018. Tomo III, p. 1889.

Tesis: II.2o.P.5 P (10a.). Semanario Judicial de la Federación y su Gaceta. 10. a época. Libro VII. Abril de 2012. Tomo 2, p. 1680.

\section{Documentos electrónicos}

GOBIERNO DE MÉXICO. Recuperado el 3 de mayo de 2020. http://www.inacipe.gob.mx/ 
comunicacion/articulos/accionpenal_arti.

php

INSTITUTO DE FORMACIÓN PROFESIONAL.

Recuperado el $1 .^{\circ}$ de marzo de 2020. http:// www.poderjudicial-gto.gob.mx/pdfs/P9.pdf

INSTITUTO NACIONAL DE ESTADÍSTICA Y GEOGRAFÍA. Encuesta Nacional de Victimización y Percepción sobre Seguridad Pública (ENVIPE) 2019. Recuperado el 1. ${ }^{\circ}$ de abril de 2020. https://www.inegi.org.mx/programas/envipe/2019/

PROCURADURÍA DE JUSTICIA DEL ESTADO MÉXICO. Recuperado el $10^{\circ}$ de marzo de 2020. https://fgjem.edomex.gob.mx/sites/ fgjem.edomex.gob.mx/files/files/Acercade/ accion\%20penal\%20privada.pdf

SECRETARÍA DE SERVICIOS PARLAMENTARIOS CENTRO DE DOCUMENTACIÓN, INFORMACIÓN Y ANÁLISIS DIRECCIÓN DE BIBLIOTECAS Y DE LOS SISTEMAS DE INFORMACIÓN. Reforma constitucional en materia de justicia penal y seguridad pública: Recuperado el 18 de junio de 2020. http:// www.diputados.gob.mx/sedia/biblio/archivo/SAD-07-08.pdf 